\title{
A Randomised Controlled Study to Investigate Effects of Bobath Based Trunk Control Training on Motor Function of Children with Spastic Bilateral Cerebral Palsy
}

\author{
Gonca Arı, Mintaze Kerem Günel* \\ Department of Physiotherapy and Rehabilitation, Faculty of Health Sciences, Hacettepe University, Ankara, Turkey \\ Email: *mintaze@hacettepe.edu.tr
}

How to cite this paper: Ar1, G. and Günel, M.K. (2017) A Randomised Controlled Study to Investigate Effects of Bobath Based Trunk Control Training on Motor Function of Children with Spastic Bilateral Cerebral Palsy. International Journal of Clinical Medicine, 8, 205-215.

https://doi.org/10.4236/ijcm.2017.84020

Received: March 20, 2017

Accepted: April 25, 2017

Published: April 28, 2017

Copyright $\odot 2017$ by authors and Scientific Research Publishing Inc. This work is licensed under the Creative Commons Attribution International License (CC BY 4.0).

http://creativecommons.org/licenses/by/4.0/

c)

\begin{abstract}
Purpose: The aim of this study was to investigate the effects of trunk control on motor function, which plays an important role in the daily activities of children with Cerebral Palsy (CP) and is often observed as a deficiency in children with CP. Material and Methods: Forty children with spastic bilateral $\mathrm{CP}$, ages between 3 to 10 years and with Gross Motor Function Classification System (GMFCS) level I, II, and III were included in this study. Children were divided into two groups using randomization and in training group; Bobath Therapy for trunk control in addition to classical physiotherapy programs was performed for 45 minutes, for two days a week, for 6 weeks. In control group, existing physiotherapy program, 45 minutes for two days a week, continued. Any addition was not made into the existing program of the control group. Modified Ashworth Scale (MAS), Pediatric Berg Balance Scale (PBBS), Trunk Control Measurement Scale (TCMS), 1 Minute Walking Test (1MWT), Timed Up and Go Test (TUG) were applied to both groups before and after 6 weeks. Moreover, trunk muscle strength of children was evaluated. Results: After therapy, differences were found in results of MAS and PBBS, and trunk extensor strength between the training group and the control group in favor of the training group $(\mathrm{p}<0.05)$. In addition, TCMS, 1MWT, TUG test and showed significant improvement compared to the average of the pre-treatment of the trunk muscle strength $(\mathrm{p}<0.05)$. In addition, after treatment, training group's averages of TCMS, PBBS, 1MWT, YUG test and all trunk muscle strength were higher compared to the ones before treatment $(\mathrm{p}<0.05)$. Conclusion: This study shows that adding exercises which aim trunk to conventional physiotherapy and exercise programs of children with $\mathrm{CP}$, affects motor function positively.
\end{abstract}




\section{Keywords}

Cerebral Palsy, Spastic Bilateral Cerebral Palsy, Trunk Control, Bobath Therapy

\section{Introduction}

Cerebral Palsy (CP) is described as a permanent but non progressive impairment of the immature brain that is affected in the prenatal, perinatal or postnatal period [1]. Spastic type of CP is the most prevalent variant (up to 70\%), which is characterized with muscle tone increase. Contractures and deformities which are proportionally consisted with the type and severity of CP can lead to postural disorders. Abnormal motor patterns, immature trunk control, abnormal tonus and disorder of postural control are affecting children's physical development negatively [1].

Trunk control is a complicated relation between skeletal muscles and neural systems. Musculoskeletal components include the biomechanic relationship between normal range of motion, spinal flexibility, muscle characteristics and single parts of the body. The primary neural components to achieve trunk control are neuromuscular synergy responses of motor process, visual, vestibular and somatosensorily systems which are included in the sensorial process. Beside these, it also includes high level integration process that leads to intuitional trunk control [2].

Children with CP have poor trunk control that is originated from different conditions. Decreased range of motion and contracture is involved with musculoskeletal problems, agonist and antagonist muscles' increased co-activation are the most important causes of disordered trunk muscle activity [2]. Trunk control is important for implementations of daily life. For healthy children, the postural and balance control is automatically done. It is difficult for children with CP to achieve this control, because of vestibular problems and balance disturbances [3].

Most researches for postural control in $\mathrm{CP}$ are studying the changes of gravity responses of lower extremity balance perturbation, standing position and then starting to walk or they are about trunk control primary for sitting. These researches show that for children with $\mathrm{CP}$, independent sitting balance and trunk control are important for walking [3].

Trunk control is defined as an early determinant of daily life and related to balance, walking and functional abilities [4]. Because of the lack of movement ability, children with CP spend more energy compared to the same aged healthy children. Due to muscle tone abnormalities, muscle weaknesses, trunk control difficulties and skeletal deformities children with CP are spending up to 2 - 3 times more energy compared to the same aged healthy children during a sub maximal exercise [5] [6] [7].

The aim of this study was to estimate the effects of motor functional exercises 
on trunk control on children with CP. For this purpose a strengthening and trunk control according to Bobath approach as well as a six week physical therapy and rehabilitation program were applied in order to observe the effects on motor functions.

\section{Method}

This study was performed at Hacettepe University, Faculty of Health Sciences at the Department of Physiotherapy and Rehabilitation between September 2012 and February 2014. Ethics approval was obtained from the Hacettepe University Medicine Faculty for Medicine, Surgery and Medication (HEK12/191-26) and from all parents a written informed consent was taken.

Inclusion criteria were,

- children living in Ankara

- children who were diagnosed with spastic bilateral cerebral palsy

- children who had a score of GMFCS [1] [2] [3] levels

- children who can walk with or without assisting devices

- children who were 3 - 15 years old

- who receive regular physical therapy twice a week

- who had no major visual impairments

- who had no orthopedic surgery and Botulinum Toxin-A injection at least for 6 months

- who were not using some drugs for inhibition of spasticity

- who did not have major auditory impairments, which leads to cooperation problems.

The children have been randomly divided in control or exercise groups. The children for the training group were encouraged for six weeks additional therapy while the control group continued their own regular physical therapy sessions twice a week for six weeks. The training group received Bobath therapy based trunk control training from the same physical therapist (GA) twice a week for 45 minutes [8].

Alfa error margin of 0.05 in work and beta value of 0.20 was set to at least 17 for a group. Considering the individual loss, it was decided that each group should be formed from 20 children. According to the power analysis which was executed in the early stages of the study, for training and control groups, in total of $40 \mathrm{CP}$ diagnosed children (exercise group $=20$, control group $=20$ ) were planned for the research. However, considering the possibility of data loss $25 \%$ it was decided total 50 children ( 25 children for each group) were to be included to the study. Within this scope 25 children in the control group were followed up, because 1 of the children who did not completed the six week physical therapy program and 4 of the children did not attend the last examination, they were excluded. In the training group 25 children were followed up, because 3 of them having not completed the six weeks trunk control education therapy and 2 of them having not attended the final examination, they were excluded. Time period for the study was designated as 18 months. Study design diagram is shown 
at Figure 1.

Inclusion criteria of the children were shown at Table 1.

TMCS was used for the functional trunk strength, postural control and trunk movement quality. The TCMS measures two main components of trunk control during functional activities: being a stable base of support, and being an actively moving body segment. Therefore, the scale consists of two main parts which are static sitting balance and dynamic sitting balance. The "static sitting balance" subscale evaluates static trunk control during movements of upper and lower limbs. Dynamic sitting balance is further divided into two subscales: selective movement control and dynamic reaching. Selective movement control of dynamic sitting balance is a scale which measures specific trunk movements in three planes (flexion/extension, lateral flexion, rotation) within the base of sup

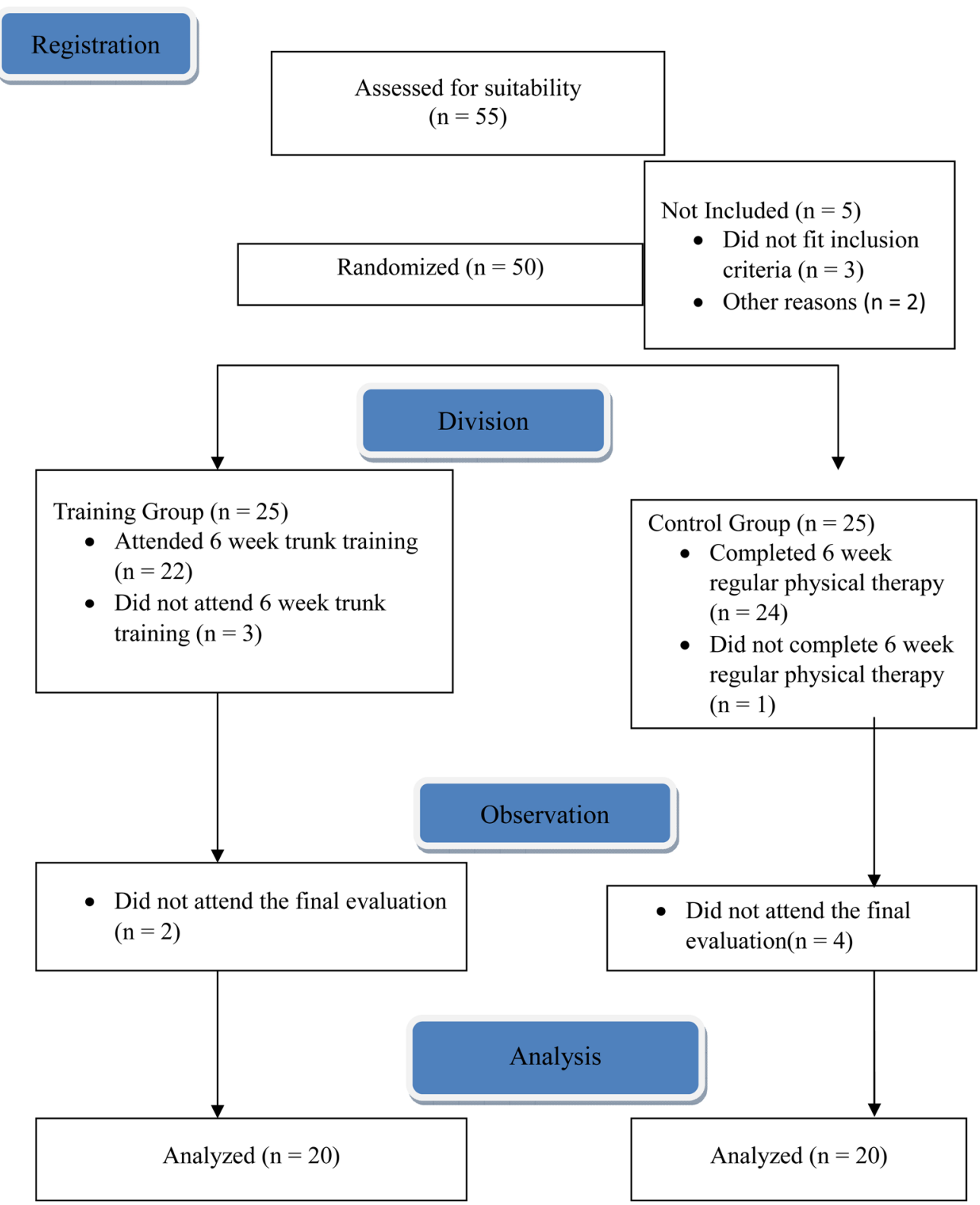

Figure 1. Diagram of the study design. 
Table 1. Definitive characteristics of the children participated in the study $(n=40)$.

\begin{tabular}{ccc}
\hline & Training Group & Control Group \\
\cline { 2 - 3 } & $\mathrm{X} \pm$ SS & $\mathrm{X} \pm$ SS \\
\hline${ }^{*}$ Age (years) & $6.55 \pm 1.91$ & $6.65 \pm 1.84$ \\
${ }^{*}$ Sex (Female/Male) (n) & $8 / 12$ & $8 / 12$ \\
GMFCS (n) & 20 & 20 \\
${ }^{*}$ Level 1 & 4 & 4 \\
${ }^{*}$ Level 2 & 10 & 11 \\
${ }^{*}$ Level 3 & 6 & 5 \\
\hline
\end{tabular}

The homogeneity between the groups was tried to be maintained. Age, gender and GMFCS levels were compared between the groups and no difference was found, Mann-Whitney U test, $\mathrm{P}>0.05$.

port. The subscale "dynamic reaching" evaluates the performance during three reaching tasks, requiring active trunk movements beyond the base of support. The total scale contains 15 items, with the subscales consisting of five, seven and three items, respectively. All items are scored on a two-, three- or four-point ordinal scale and administered bilaterally in case of clinical relevance. The total score of the TCMS ranges from 0 (lowest performance) to 58 (best performance). TCMS has been tested for reliability and validity in children with $\mathrm{CP}$ who were 8 - 15 years old [9].

To investigate functional balance in activities of daily life, Franjoine et al. developed Pediatric Berg Balance Scale which is a regulated version of Berg Balance Scale for children. The test has 14 sections and every section is scored from 0 to 4 . The highest score is 56. PBBS is built up from easy to hard tasks. Functional processing was recently edited. Time section parts of the scale for static posture persistence were reduced and instructions were simplified for pediatric population [10].

Timed up and go and 1 minute walking test are used for the functional movement skills. Timed up and go test is used for measuring different components like walking speed, postural control, functional mobility and balance. Andersson et al. (2003) used this test to evaluate the results of strengthening program for adults with CP [11].

Back muscles were assessed in prone position; rectus abdominus was assessed in supine position, with manual muscle testing to determine trunk muscles.

Training group received trunk control exercise program based to Bobath therapy for six weeks. The program was applied twice a week. The control group continued only their regular physical therapy program without additional trunk control exercises. Regular physical therapy program includes positioning and reducing spasticity, strengthening abdominal, back and lower extremity muscles, sitting and standing balance and walking exercises.

The children were monitored whether they attend the 45 minute twice a week program excluded from the program. Both groups were evaluated in the beginning and at the end after six weeks of the program.

Measured data were presented as arithmetical mean \pm standard deviation $(\mathrm{X} \pm$ 
STD). Numeric data were evaluated as numbers and percentages. Relevance was accepted $p<0.05$ in $95 \%$ of confidence interval. Non parametric Wilcoxon Signed Ranks Test was used for comparing ordinal parameters intragroup after before treatment whereas another non parametric Mann-Whitney $U$ test was used for comparing ordinal parameters intergroup after before treatment. Spearman Correlation Test was applied to investigate the relation between groups. Stratified Randomisation method was prefered based on the fact that randomized selection can affect the study statiscally while assigning children to the groups.

\section{Results}

Forty children with CP were included in the study. Muscle strength differences between two groups before and after the treatment are presented in Table 2.

Trunk control, spasticity, timed up and go walking test, 1 minute walking test and Pediatric Berg Balance Scale results before and after treatment are shown in Table 3 .

The differences between groups after treatment are demonstrated in Table 4.

Table 2. Muscle strength values in groups before and after treatment.

\begin{tabular}{|c|c|c|c|c|}
\hline & & $\begin{array}{c}\text { Before Treatment } \\
\text { Mean } \pm \text { STD }\end{array}$ & $\begin{array}{c}\text { After Treatment } \\
\text { Mean } \pm \text { STD }\end{array}$ & $\mathrm{p}$ \\
\hline \multirow{4}{*}{$\begin{array}{l}\text { Training } \\
\text { Group }\end{array}$} & Rectus Abdominus & $3.08 \pm 0.46$ & $3.40 \pm 0.45$ & 0.001 \\
\hline & Right Obliques & $2.75 \pm 0.46$ & $2.85 \pm 0.43$ & 0.020 \\
\hline & Left Obliques & $2.75 \pm 0.46$ & $2.85 \pm 0.43$ & 0.020 \\
\hline & Back Muscles & $3.10 \pm 0.47$ & $3.51 \pm 0.40$ & 0.001 \\
\hline \multirow{4}{*}{$\begin{array}{l}\text { Control } \\
\text { Group }\end{array}$} & Rectus Abdominus & $3.10 \pm 0.47$ & $3.15 \pm 0.41$ & 0.180 \\
\hline & Right Obliques & $2.60 \pm 0.48$ & $2.61 \pm 0.46$ & 0.317 \\
\hline & Left Obliques & $2.80 \pm 0.40$ & $2.83 \pm 0.43$ & 0.157 \\
\hline & Back Muscles & $3.03 \pm 0.56$ & $3.03 \pm 0.56$ & 1.000 \\
\hline
\end{tabular}

Table 3. Trunk control, spasticity, timed up and go, 1 minute walking test, pediatric berg balance scale values of the groups before and after treatment.

\begin{tabular}{lcccc}
\hline & & $\begin{array}{c}\text { Before Treatment } \\
\text { Mean } \pm \text { STD }\end{array}$ & $\begin{array}{c}\text { After Treatment } \\
\text { Mean } \pm \text { STD }\end{array}$ & $p$ \\
\hline TCMS & $28.25 \pm 7.17$ & $33.40 \pm 6.84$ & $<\mathbf{0 0 1}$ \\
Graining & MAS & $3.00 \pm 0.73$ & $2.50 \pm 0.51$ & $<\mathbf{0 . 0 0 2}$ \\
& TUG & $15.30 \pm 2.98$ & $12.82 \pm 2.83$ & $<\mathbf{0 . 0 0 1}$ \\
1MWT & PBBS & $173.50 \pm 39.21$ & $197.50 \pm 36.19$ & $<\mathbf{0 . 0 0 1}$ \\
Group & TCMS & $40.85 \pm 4.46$ & $45.95 \pm 3.79$ & $<\mathbf{0 . 0 0 1}$ \\
& MAS & $30.70 \pm 6.84$ & $32.40 \pm 5.41$ & 0.278 \\
& TUG & $3.00 \pm 0.73$ & $2.90 \pm 0.64$ & 0.157 \\
& PMWT & $14.40 \pm 2.98$ & $13.74 \pm 2.65$ & 0.401 \\
\hline
\end{tabular}


The correlation between TCMS, functional movement tests and Pediatric Berg Balance Scale is shown in Table 5. There was a significant positive correlation between the TCMS total score, the PBBS and the 1 MWT and negative correlation between the timed up and go test $(\mathrm{p}<0.05)$.

\section{Discussion}

This study was designed in consideration of the hypothesis that impaired trunk control could be important for children with CP, because trunk control affects activities of daily life and motor control negatively. After the exercise program when both groups were compared, the training group showed significant increase in muscle tone, balance and trunk muscle strength. Additionally the training group achieved more positive progression than the control group.

Several researches have proved that impaired trunk control is an important motor disorder for children with CP and can affect the performance of daily life activities such as sitting, reaching and walking negatively. Also many studies compared trunk control in healthy children with children who had CP and they predicted that achievement of trunk control is important. According to these facts, physical therapy and rehabilitation approaches which are designed in correlation whit these findings are assumed to be more successful for trunk control and motor functions. In the light of these, when children with poor trunk control are evaluated with this manner and had the adequate treatment designed for them, their chance for a good quality of life is enhanced [12].

At the present time The International Classification of Functioning, Disability and Health for Children and Youth (ICF-CY) is an important to plan programs and implement interventions [13] [14]. In our study TCMS was used for the assessment of the main topics such as static sitting balance, selective motor

Table 4. Intragroup values after treatment.

\begin{tabular}{ccccccc}
\hline & \multicolumn{2}{c}{$\begin{array}{c}\text { Training Group } \\
(\mathrm{N}=20)\end{array}$} & \multicolumn{2}{c}{$\begin{array}{c}\text { Control Group } \\
(\mathrm{N}=20)\end{array}$} & \multicolumn{2}{c}{ Mann-Whitney $\mathrm{U}$} \\
\cline { 2 - 7 } & $\mathrm{X}$ & $\mathrm{SD}$ & $\mathrm{X}$ & $\mathrm{SD}$ & $\mathrm{Z}$ & $\mathrm{p}$ \\
\hline TCMS & 33.40 & 6.84 & 32.40 & 5.41 & -0.420 & 0.674 \\
MAS & 2.50 & 0.51 & 2.90 & 0.64 & $-\mathbf{1 . 9 9 0}$ & $\mathbf{0 . 0 4 7}$ \\
TUG & 12.82 & 2.83 & 13.74 & 2.65 & -0.839 & 0.401 \\
1MWT & 1972.5 & 369.19 & 1982 & 331.74 & -0.027 & 0.978 \\
PBBS & 45.95 & 3.79 & 43.20 & 3.64 & $\mathbf{- 2 . 0 7 6}$ & $\mathbf{0 . 0 3 8}$ \\
\hline
\end{tabular}

Table 5. Relation between timed up and go, 1 minute walking test, pediatric berg balance scale.

\begin{tabular}{lcccc}
\hline & & $\begin{array}{c}\text { 1 Minute Walking } \\
\text { Test }\end{array}$ & $\begin{array}{c}\text { Timed Up and } \\
\text { Go Test }\end{array}$ & $\begin{array}{c}\text { Pediatric Berg } \\
\text { Balance Scale }\end{array}$ \\
\hline $\begin{array}{c}\text { Trunk Control } \\
\text { Measurement } \\
\text { Scale }\end{array}$ & $\mathrm{r}$ & 0.986 & -0.979 & 0.812 \\
$(0-56$ points $)$ & $\mathrm{p}$ & $<0.001$ & $<0.001$ & $<0.001$ \\
\hline
\end{tabular}


control of dynamic sitting balance and dynamic reaching for trunk control in sitting position. TCMS is a new test for trunk assessment which enables clinic information about trunk control by walking.

Some studies investigated trunk control is an important indicator of motor functions [15]. These studies reveal that trunk control is related to balance, walking and functional abilities which have an important role in daily life activities [16].

Specialist for nuclear physicist Gracovetsky developed a new biomechanical approach for body locomotion that is named spinal machine theory. According to his researches, he showed that people without lower extremities is capable of walking while using only their tuberositas ischiadica bones [17]. The assumption of walking and motor function is affected of body muscle strength; training group received special and amplified trunk exercises. After therapy the training group had significant strength improvement on trunk muscles whereas the control group had no significant differences on trunk muscle strength after the regular therapy program. These findings indicate that even if only for six weeks additional to the exercise program of the physical therapy program increases the strength of the trunk muscles. The increase of body muscle strength has positive effects on static and dynamic trunk control. Verheyden et al. revealed in different studies, trunk control assessment is related to balance, walking and functional abilities [18].

In our study when the trunk control results of both groups were compared, both groups had improvements. The training group had the most significant improvements after therapy. In this case, this also means that the TCMS test clearly shows the improvements of trunk control and how important the special trunk exercises.

Trunk control in children with CP can be assessed with tests mentioned before, but it can be also assessed by muscle strength and functional parameters. Therefore, a comprehensive evaluation was made in our study.

Literature researches show that Pediatric Berg Balance Assessment has been widely used for the assessment of functional balance. In our study positive scores are obtained in PBBS intergroup in favor of the training group before and the after treatment. Even though studies do not suggest that PBBS does not have a specific test battery for assessments of trunk control, PBBS includes tasks evaluating balance performances during sitting and standing, and the fact that it is related to trunk control proves it is not only a passive moving segment [19]. This result is important because it indicates that the trunk affection affects the functional balance.

Improvements are observed for both groups in results of the Timed up and go and 1 minute walking functional movement test after treatment. The training group had significant progress after six weeks of exercise therapy. The intergroup relation of the exercise and control group had no significant differences before and after treatment. However our results indicate that 1 MWT is a cheap, useful, simple test and it does not need any expensive equipment to assess gross motor function in the clinic. So this test can be a standard while assessing children with $\mathrm{CP}$ who are able to walk. 
The relationship between functional movement tests and trunk control are supported with many studies which show that a multiple layer effect of erect posture while walking has a significant role. In our study PBBS, TUG and 1 minute walking tests had a significant positive relationship with TCMS total scores. These results demonstrate the relationship between trunk influence and functionality, and the critical role trunk plays in postural balance.

Spastic Bilateral children are affected from lower extremity spasticity. Barnes et al. and Filloux support the results for our study. They suggest that spasticity in lower extremity causes decrease in motor functional abilities, distortion of coordination in synergetic muscles and co-contraction increase among antagonistic muscles; this results in increase in trunk influence [19] [20]. Comparison of our groups before and after treatment yields significant positive improvement in favor of the training group. The fact that control group did not have a significant difference in muscle tone whereas training group has positive improvement supports that muscle tone is related to trunk control. This muscle tone differences between groups are linked with trunk exercises.

The strengths of our study are that all children with CP had the same characteristics and all the groups were randomly divided in homogenous groups. Our study was planned as a randomized controlled trial, which compares before and after treatment results. This study was planned according to our countries physical therapy norms and since it would be not ethical for the control group not to receive physical therapy, control group consists of children who receive regular physical therapy. Another strength of our study is that Bobath approach was planned and applied by a physiotherapist who educated 8 weeks of basic Bobath training.

\section{Limitations}

To evaluate the efficiency of the treatment is often not easy. This is due to the fact that it is very time consuming to get some objective assessment parameters. In the clinic, subjective parameter which has high validity and reliability are used; however these parameters usually are not enough to determine the quality of movement.

The assessment used in our study revealed some objective results; however none of the methods can assess muscle structure. Therefore, further researches should include some electromyography parameters.

The literature shows that Bobath therapy creates some differences after 0.5 - 1 year [21] [22] [23] [24]. The other limitation was that the therapy duration and interval. In our study the therapy lasted only for six weeks (2 sessions per week). Because it was a master thesis with time limitations longer follow up could not be done. In spite of this circumstance, the follow up of our patients continues in the clinic. After therapy results will be collected and reported.

\section{Conclusion}

Even though that the training group had more significant improvements than 
the control group, the only significant differences were found in lower extremity spasticity, muscles of the trunk and PBBS scores.

\section{Declaration of Interest}

The authors report no declarations of interest; the research was funded solely by the authors themselves. The authors report no conflict of interest.

\section{References}

[1] Kerem Gunel, M. (2009) Rehabilitation of Children with Cerebral Palsy from a Physiotherapist's Perspective. Acta Orthopaedica et Traumatologica Turcica, 43, 173-180. https://doi.org/10.3944/AOTT.2009.173

[2] Nicholson, J.H., Morton, R.E., Attfield, S. and Rennie, D. (2001) Assessment of Upper-Limb Function and Movement in Children with Cerebral Palsy Wearing Lycra Garments. Developmental Medicine \& Child Neurology, 43, 384-391.

[3] Van der Heide, J.C. and Hadders-Algra, M. (2005) Postural Muscle Dyscoordination in Children with Cerebral Palsy. Neural Plasticity, 12, 197-203.

https://doi.org/10.1155/NP.2005.197

[4] Furukawa, A., Iwatsuki, H., Nisiyama, M., Nii, E. and Uchida, A. (2001) A Study on the Subjective Well-Being of Adult Patients with Cerebral Palsy. Journal of Physical Therapy Science, 13, 31-35. https://doi.org/10.1589/jpts.13.31

[5] Ohrvall, A.M., Eliasson, A.C., Lowing, K., Odman, P. and Krumlinde-Sundholm, L. (2010) Self-Care and Mobility Skills in Children with Cerebral Palsy, Related to Their Manual Ability and Gross Motor Function Classifications. Developmental Medicine \& Child Neurology, 52, 1048-1055. https://doi.org/10.1111/j.1469-8749.2010.03764.x

[6] Rose, J., Gamble, J.G., Burgos, A., Medeiros, J. and Haskell, W.L. (1990) Energy Expenditure Index of Walking for Normal Children and for Children with Cerebral Palsy. Developmental Medicine \& Child Neurology, 32, 333-340. https://doi.org/10.1111/j.1469-8749.1990.tb16945.x

[7] Hanna, S.E., Rosenbaum, P.L., Bartlett, D.J., Palisano, R.J., Walter, S.D., Avery, L., et al. (2009) Stability and Decline in Gross Motor Function among Children and Youth with Cerebral Palsy Aged 2 to 21 Years. Developmental Medicine \& Child Neurology, 51, 295-302. https://doi.org/10.1111/j.1469-8749.2008.03196.x

[8] Knox, V. and Evans, A.L. (2002) Evaluation of the Functional Effects of a Course of Bobath Therapy in Children with Cerebral Palsy: A Preliminary Study. Developmental Medicine \& Child Neurology, 44, 447-460. https://doi.org/10.1111/j.1469-8749.2002.tb00306.x

[9] Heyrman, L., Molenaers, G., Desloovere, K., Verheyden, G., De Cat, J., Monbaliu, E. and Feys, H. (2011) A Clinical Tool to Measure Trunk Control in Children with Cerebral Palsy: The Trunk Control Measurement Scale. Research in Developmental Disabilities, 32, 2624-2635. https://doi.org/10.1016/j.ridd.2011.06.012

[10] Franjoine, M.R., Gunther, J.S. and Taylor, M.S. (2003) Pediatric Balance Scale: A Modified Version of the Berg Balance Scale for the School-Age Child with Mild to Moderate Motor Impairment. Pediatric Physical Therapy, 15, 114-120. https://doi.org/10.1097/01.PEP.0000068117.48023.18

[11] Andersson, C., Grooten, W., Hellsten, M., Kaping, K. and Mattsson, E. (2003) Adults with Cerebral Palsy: Walking Ability after Progressive Strength Training. Developmental Medicine \& Child Neurology, 45, 220-228. 
https://doi.org/10.1111/j.1469-8749.2003.tb00335.x

[12] Yılmazyürk, Ş., Üçkardeş, A.O. and Eker, M. (2005) Yürüme Analizi. In: Özcan, H. Ed., Cerebral Palsy, Boyut, Istanbul, 95.

[13] Rosenbaum, P., Paneth, N., Leviton, A., et al. (2007) A Report: The Definition and Classification of Cerebral Palsy. Developmental Medicine \& Child Neurology, 49, 814. https://doi.org/10.1111/j.1469-8749.2007.tb12610.x

[14] Rosenbaum, P. and Stewart, D. (2004) The World Health Organisation International Classification of Functioning Disability and Health: A Model to Guide Clinical Thinking, Practice and Research in the Field of Cerebral Palsy. Seminars in Pediatric Neurology, 11, 5-10. https://doi.org/10.1016/j.spen.2004.01.002

[15] Verheyden, G., Williams, A.M., Ooms, L., et al. (2007) Validity of the Trunk Impairment Scale as a Measure of Trunk Performance in People with Parkinson's Disease. Archives of Physical Medicine and Rehabilitation, 88, 1304-1308. https://doi.org/10.1016/j.apmr.2007.06.772

[16] Assaiante, C., Mallau, S., Viel, S., et al. (2005) Development of Postural Control in Healthy Children: A Functional Approach. Neural Plasticity, 12, 109-118. https://doi.org/10.1155/NP.2005.109

[17] Gracovetsky, S.A. (2001) Analysis and Interpretation of Gait in Relation to Lumbopelvic Function. 4th Interdisciplinary World Congress on Low Back and Pelvic Pain, Montreal, Canada.

[18] Verheyden, G., Nieuwboer, A., Mertin, J., Preger, R., Kiekens, C. and De Weerdt, W. (2004) The Trunk Impairment Scale: A New Tool to Measure Motor Impairment of the Trunk after Stroke. Clinical Rehabilitation, 18, 326-334. https://doi.org/10.1191/0269215504cr733oa

[19] Barnes, M., McLellen, L. and Suttar, R. (1994) Spasticity. In: Greenwood, R.J., Barnes, M.P., McMillan, T.M. and Words, C.D., Eds., Neurological Rehabilitation, Churchill Livingstone, Edinburg, 161-172.

[20] Filloux, F.M. (1996) Neuropathophysiology of Movement Disorders in Cerebral Palsy. Journal of Child Neurology, 11, 5-12. https://doi.org/10.1177/0883073896011001S02

[21] Ketelaar, M., Vermeer, A., Hart, H., Beek, E.P. and Helders, P.M.J. (2009) Effects of a Functional Therapy Program on Motor Abilities of Children with Cerebral Palsy. Physical Therapy, 81, 1534-1545. https://doi.org/10.1093/ptj/81.9.1534

[22] Palmer, F.B, Shapiro, B.K, Wachtel, R.C., Allen, M.C., Hiller, J.E, Harryman, S.E., Mosher, B.S., Meinert, C.L. and Capute, A.J. (1988) The Effects of Physical Therapy on Cerebral Palsy. A Controlled Trial in Infants with Spastic Diplegia. The New England Journal of Medicine, 318, 803-808. https://doi.org/10.1056/NEJM198803313181302

[23] Trahan, J. and Malouin. F. (1999) Changes in the Gross Motor Function Measure in Children with Diffrens Type of Cerebral Palsy: An Eight-Month Follow-Up Study. Pediatric Physical Therapy, 11, 12-17. https://doi.org/10.1097/00001577-199901110-00003

[24] Hazneci, B. (2005) Cerebral Palsy Rehabilitasyonu. In: Kalyon, T.A., Ed., Fiziksel Tip ve Rehabilitasyon, Gata Basımevi, Ankara, 545-556. 
Submit or recommend next manuscript to SCIRP and we will provide best service for you:

Accepting pre-submission inquiries through Email, Facebook, LinkedIn, Twitter, etc. A wide selection of journals (inclusive of 9 subjects, more than 200 journals)

Providing 24-hour high-quality service

User-friendly online submission system

Fair and swift peer-review system

Efficient typesetting and proofreading procedure

Display of the result of downloads and visits, as well as the number of cited articles Maximum dissemination of your research work

Submit your manuscript at: http://papersubmission.scirp.org/

Or contact ijcm@scirp.org 